Iris M. Zavala

Universitat Pompeu Fabra. Barcelona

\title{
EL AMOR, LA ESPINA CLAVADA Y LA ANGUSTIA EN ROSALÍA DE CASTRO
}

Desde la Biblia, Platón, la mística, la poesía lírica, el amor es un deseo de plenitud que nos empuja hacia el otro. Hacer de dos Uno, es la fórmula de ese ideal. ¿Imposible? $\mathrm{El}$ amor cortés transmuta ese imposible en una ética, diviniza a la mujer elevándola al rango de lo inalcanzable. Modificación de Eros que permite hacer de la palabra mediación necesaria, ficción que "no cesa" de producir efectos de amor. Freud vio con claridad la fecundidad del erotismo en la ética. En el siglo XIX, Eros se democratiza, la literatura folletinesca, que se irá conociendo como novela rosa, narra el triunfo de la pasión sobre cuanto la obstaculiza, y con el surrealismo llega su desmesura, el amour fou, el amor trágico.

El amor, que no cesa de escribirse, nos sitúa en el siglo XIX, época de esplendor, buscando ese imposible hacer de dos Uno. Surge una cultura de las lágrimas, y se describen con minuciosidad las ausencias, los desvelos, las angustias... La novela sentimental se irá transformando en novela rosa. Desde María, la hija del jornalero, best seller de la época, el amor, en efecto, busca hacer de dos Uno, y el texto se regodea, por eso, en el encuentro. Novela, teatro y poesía lírica descubren las emociones de ese sentimiento avasallador que promete dichas sin fin... El Romanticismo tiene como horizonte la subjetividad dominante en su época, y el amor es la espiral a la que la época arrastra todo.

En Rosalía, en sus textos, encontraremos que el movimiento dialéctico de la modernidad se vuelve irónicamente contra la fuerza motriz de los valores -cristianos- de la integridad del alma y el deseo de verdad. En otro momento he sugerido que a mediados del siglo XIX la ironía romántica pone de relieve que ni los sentimientos dejan de ser disonantes: Rosalía llega a la burla de sí misma, a la duda; la suya es una voz que conoce ell dolor y el miedo -conoce aquel sentimiento que Kirkegaard precisará con el término de angustia. El nuevo lenguaje es "otro", y esa pérdida va a llegar a ser difícilmente accesible, porque las relaciones materiales lo enmascaran, lo recusan y lo desparraman. El sentimiento que se percibe en sus textos es de turbación, aquel susto y caída de potencia que antecede a la angustia; ese afecto que, no reprimido, va a la deriva.

La angustia es lo que no engaña, escribe Lacan, aquella imposible visión que amenaza desde sus propios ojos, donde el sujeto está ceñido, concernido, interesado en lo más íntimo de sí mismo. El factor fascinante de sus versos es la voz, ese objeto perdido y de repente encontrado, en la conflagración del dolor por la introducción del otro. Esta cuestión íntima, el objeto a, y que Lacan define como causa del deseo, la mira del deseo, es algo en ti más que tú. El objeto a puede conducirnos al punto privilegiado, que en su poesía surge por medio de la voz, y ese algo en sí más que ella misma es "la espina clavada". Esa "espina" rosaliana se puede entender a partir de la pregunta ¿qué quiere el Otro?, ¿qué me quiere? Su "espina" es una pulsión invocante, un desesperado llamado al Otro. 
En este punto, Rosalía toca lo unheimlich, lo siniestro del deseo del Otro que anima su angustia. La idea en nuestra escritora es lo "fantasmático" del lacanismo, y esa turbación que aparece en lo que Schelling llama el "poder B", la condición de posibilidad y de imposibilidad de la idea. La belleza como el velo de lo horrible -lo siniestro- del vórtice caótico de lo Real. La angustia en ella es la experiencia límite de capturar lo Real. Su escritura es un perpetuo recuestionamiento del deseo, y la saudade equivale a un indicador, como señal de la única relación que no engaña. La angustia también existe en la mujer, y está enlazada a la posibilidad de no poder; Kierkegaard, nos recuerda Lacan en su seminario, dice incluso que la mujer está más abierta a la angustia. ¿Habrá que creerle?

Rosalía sabe que desde el momento que habla ya está implicado su cuerpo, y presiente además lo que Homero ya conocía: que detrás del labio está el recinto de los dientes y de la mordedura. Una lectura atenta de su poesía nos invita a multiplicar los problemas que la alienación -ese fantasma de Kierkegaard y Marx- plantea como demonio de la moderna cultura del progreso. En Rosalía, el poder de su mente, al volverse hacia el interior, se convierte en su prisión: la espina clavada, que se ríe de sus aspiraciones. El lenguaje es, en cierto modo, el lugar de la falta. La poeta sabía algo que Hegel subrayó en su Fenomenología, que el lenguaje es trabajo, que allí el sujeto hace pasar su interior al exterior.

Los problemas de esta escritora, no son sólo suyos, sino la expresión angustiada de tensiones mayores que agitaban a la sociedad española en vías de la modernidad. Los caminos elaborados por esta gran romántica indican el campo central del deseo y lo Real de la angustia. Este es su legado.

Volvemos al principio, el legado del siglo XIX y sus saberes, y el desarrollo de los textos dialógicos; pues un texto dialógico -como el rosaliano- es aquel que soporta la prueba del comentario, y permite medir si la respuesta que aporta a las preguntas que plantea ha sido, o no, rebasada. En este sentido es preciso crear redes simbólicas, el texto dialógico plantea la potencia y el enigma del mal en el corazón mismo del fenómeno humano. Es decir, toca lo Real.

La ironía ambivalente rosaliana, nos obliga a una lectura coyuntural. Aludo, evidentemente, a la modernidad, y la batalla feroz en el terreno de la relación entre los sexos. Buena parte de la gran literatura "realista" incorporó el personaje de la "histérica"; esta se puede encontrar en las óperas de Wagner, en Augusto Strindberg, Otto Weininger, Kafka, Munch, y, claro, nuestro Galdós. El malestar y la crisis de las relaciones sexuales que estos autores mostraron y describieron, es aún nuestra. Grandes hecatombes y tormentas han debido ocurrir para transformar aquellas ingenuas y hermosas escenas armónicas de la pareja que encontramos en La flauta mágica mozartiana. El péndulo osciló hacia el otro extremo, poniendo al descubierto la relación antagonista radical entre los sexos. Lo que nos dejan en claro las grandes poemas rosalianos es que el hombre y la mujer no son complementarios, que no existe nada que pueda llamarse una armonía preestablecida, y que cada sexo le plantea una amenaza a la identidad del otro.

Es entonces el orden simbólico lo que Rosalía elabora: el espejismo del amor, esa ofuscación que la mirada y la voz desatan. Pero llega a sutiles especulaciones y finas ironías para mostrar lo que en la sociedad no marcha: la relación entre los sexos, y que el amor produce angustia, desasosiego, cuando no dolor. La gallega parecería sugerir que 
el goce femenino y el masculino son heterónimos, que siempre hay algo indescifrable del goce del otro sexo. Si mi hipótesis es aceptable, su poesía se articula mediante un proceso de histerización del texto y del lector, que supone abrir en el discurso una interrogación dirigida al Otro. Si histerizar, según Lacan, es suscitar un deseo de saber la causa del sufrimiento, el texto se vuelve analizable a condición de que el lector se incluya. Toma así la forma de una pregunta; la histerización supone una apertura al Otro y un cambio de posición del sujeto en el discurso.

Esta idea sugiere que hay una afinidad profunda entre el deseo de la mujer y la modernidad. Sus poemas encarnaban la idea de la mujer como ser deseante. La lectura de sus poemas y prosas nos revelan que los excesos vienen a "presentificar" la verdad del discurso idealizante sobre el amor "romántico". En este punto, querría retomar, una vez más, las analogías con El Banquete de Platón en la lectura lacaniana. Se recordará que el diálogo es toda una interrogación sobre el amor: la tesis de Diótima que hace del amor la metonimia del bello ideal, y Alcibíades, que según Lacan "presentifica" la verdad del discurso idealizante de Diótima. Debemos definir los términos: erastés y erómenos, recordando que la discusión gira en torno a la comparación que propone Fedro en su primer discurso. Se pregunta cuál de los dos sacrificios es más grande: el de Alcestes, que sustituye a su amado en la muerte, que acepta morir en lugar de su amado, Admeto. $\mathrm{O}$ el de Aquiles y Patroclo, pues Aquiles renuncia a la vida por Patrocolo, ya muerto. El sacrificio más grande es el del erómenos, el amado, es decir el objeto de amor: Aquiles era el amado de Patroclo, que tenía diez años más. Aquiles nos indica la metáfora del amor: el amado se ha cambiado en erastés, deseante.

Pero su ironía no sólo es la "forma de lo paradójico" (en definición de Schlegel), sino una forma de histerización, aquella que plantea la paradoja de "¿soy hombre o mujer?", y el enigma del che vuoi? Si miramos las cosas con rigor, Rosalía no sólo pone en escena la verdad: la mentira y el engaño de las convenciones sociales; sino el espejismo del amor: esa ofuscación que la mirada y la voz desatan. En mi lectura, los textos rosalianos se hacen legibles retroactivamente, desde el paradigma del futuro que prefiguran. Y eso le da a su obra el valor que, hoy, tiene. 